\title{
مي زيادة
}

\section{أديبة بين الواقعيّة والرومنطيقيّة}

\author{
الاكتور سردارِ اصلاني
}

الأستاذ المشارى بجامعة أصفهان

الملخص:

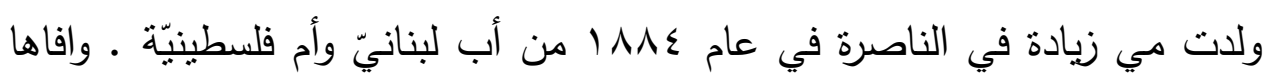

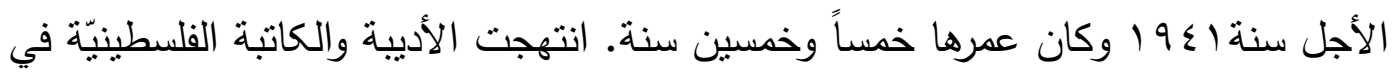

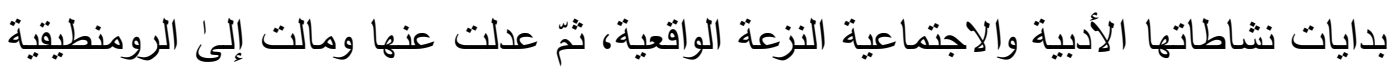

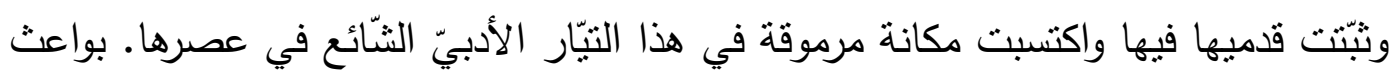

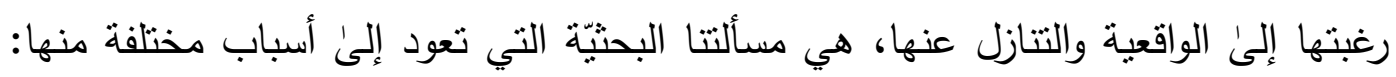
ظروفها المعيشية الأسريّة والاجتماعيّة وتجاربها الخاصة فيها، وغئها وغرامياتها وأحلامها المبتورة

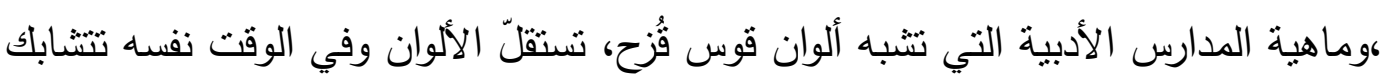

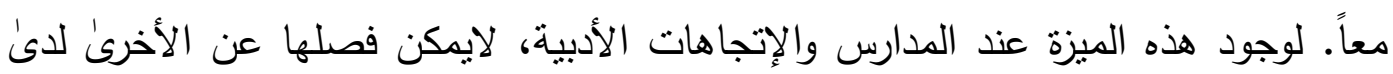

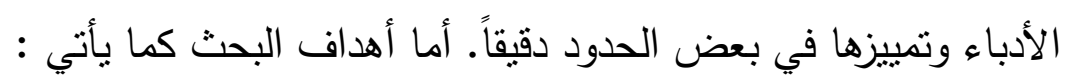

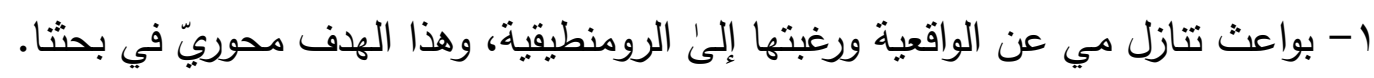
r- بعالم الواقعية والرومنطيقية في آنار ها. r- بيان منزلة مي كأديبة، وكاتبة اجتماعية ومفكرة ذات نأثثر نافذ في أوساط التهاء الأدباء

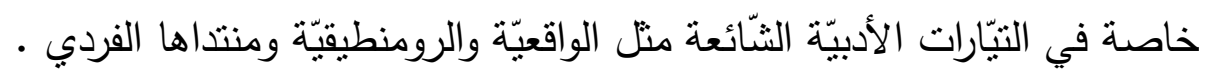

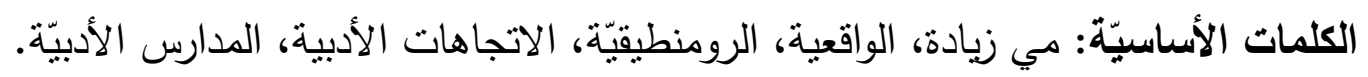
المقدمة :

نزع الأدباء في عصر عانت فيه مي، مذاهب أدبيّة مختلفة من الواقعية

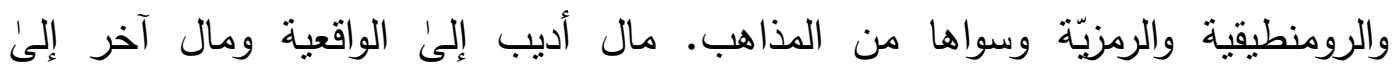

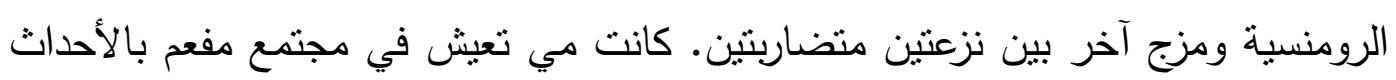

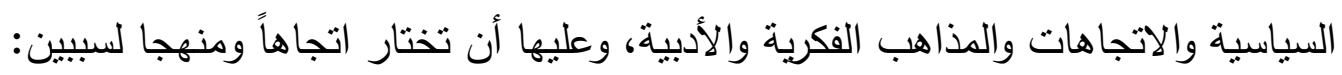

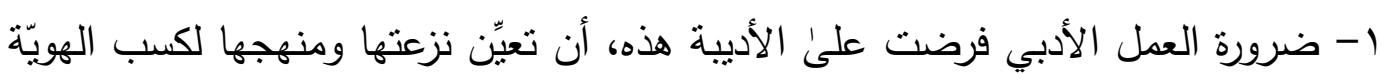

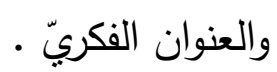

r- السلائق والميول الذاتيّة تؤدّبي عفواً وطبيعياً إلى انتهاج الأديبة منهجا أومناهج خاصة

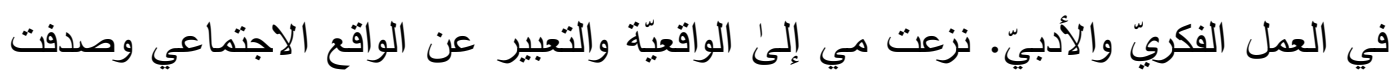

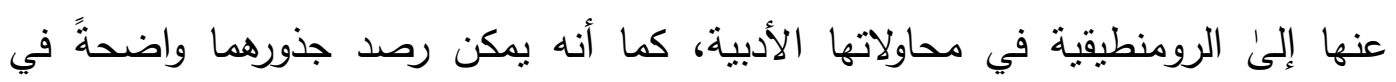


أعمالها الأدبية. اكترثت للواقع الاجتماعى والثعبي وأعتتت بما يجري في حياة الناس وواقعهم الميداني ومايسوده من الأعراف والتقاليد، منها المرغوبة الصالحة وغير المرغوبة الفاسدة والكفاح لاستئصال جذور الأخيرة من بنية المجتمع. وفي جانب آخر من حياتها اهتمت مي بالخيال والعالم الخياليّ والعاطفي أو الرومنطيقي وجنحت بروحها السامية الى لئ عالم الأحاسيس والخوالج الذاتيّة.حياتها العائليّة والفرديّة كانت مهيئة لنزعتها إلى الواقعية والرومنطيقية وظهورمعالمهما على شخصيتها وأعمالها الأدبية تُظهر بوضوح المميزات الواقعية و تتجلى الصفات والمعالم الرومنطيقية عندها. هذه الحالة ليست عجيبة أو خارقة ،لأن الوجوه الفكرية والرموز الأدبية العملاقة لاتتحصر في اتجاه وميزة أدبية واحدة.كلّما توسّعت نفسيّة الفرد، نوّسعت أبعادها وزواياها الفكرية. الثخصية الرسالية في الأدب تحاول الإصدلاح الاجتماعي بالواقع والنزعة الواقعية والممارسة المكثوفة العلنية. وبعد مواجتها بالروادع والصخور الصلبة الاجتماعية، تغيّر مجراها وتخطو خطوات رومنسية خيالية وتقاوم المجتمع الفاسد بتقاليده البالية الفاسدة بأساليب غير شفافة وهي الرومنطيقة التي تؤدي في النهاية إلى الأحلام والرؤى' الفردية وأخيراً اللّوذ بالخيال البحت الذى بُسمّى ي في المصطلح

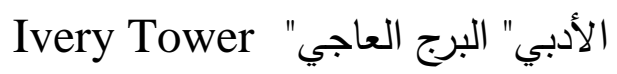
ويعد خروجا من واقع المجتمع (') وفراراً منه. تدل النزعتان على عظمة كيان مي الوجودي والنواحي والملتقيات المتعددة فيها. لهذا خلال دراسة حول شخصيتها وآثارها، خطرت ببالي بعض الأسئلة التى طرحناها في الملخص إطار الأهداف.السؤال المحوري وبيت القصيد في بحثنا هو : ما هي بواعث تتازل مي من الواقعية وجنوحها إلى الرومنطيقية؟ خلفية البحث : مون

هنالك بحوث ودراسات وأعمال كثثرة في موضوع مي زيادة، منها: لمي وجبرانه لجميل جبر ، و امي زيادة《 لسلمى حفار الكزبريّ و 》مي في حياتها المضطربةه لجميل جبر ، و اذكرى' فقيدة الأدب النابغة مي" لهدى' هانم شعراوي و لامحنة الآنسة ميه لأحمد حسن الزبّات و 》أطياف من حياة مي « لطاهر الطناجي و 》محاضرات عن مي زيادة" لمنصور فهمي و امي ضحيّة الفكرة الثابتة) لمارون العبود و لازيارة ميه لأمين الريحانيّ

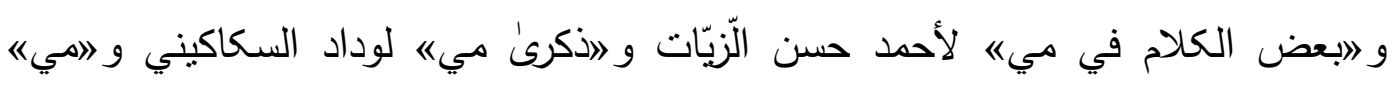

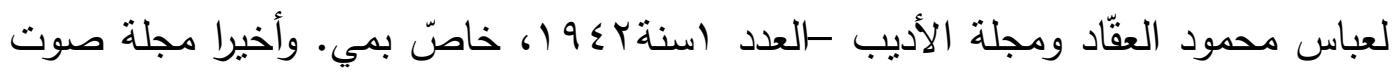

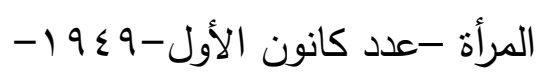

بعد المحاولة الكافية ما وجدنا بحثًا في موضوع نحن بصدد تقديمه. نوع البحث في مقالتتا، يعدّ تتمويّا ومناهجنا فيه مؤلّفة من الوصفيّ، والعليّ والاستتباطيّ والتاريخيّ. 
هذه الترجمة تساعدنا في كثف المجاهل لحياة مي وآرائها. لو دققّا فيها، هنالك قضايا مهمة وخطيرة تشاعد القارئ والباحث لتعرُّف الزوايا الخافية والكامنة لأفكارها وسليقتها الفكرية والأدبية ،خاصة اتجاهها الأدبي الذي مال إلى الرومنطيقية واستغرق أكثر مدة من عمرها • اولدت مارى -مي- إبنة إلباس زيادة في الناصرة حيث كان أبوها اللبنانيّ الأصل يدرّس في أحد المعاهد الحكومية. وما إن بلغت الرابعة عشرة من عمرها حتى انتقل بها ذووها إلى لبنان وأُدخلت مَدرسة الراهبات في عينطورة، وقد عرفت إذ ذالك بميلها الثديد إلى

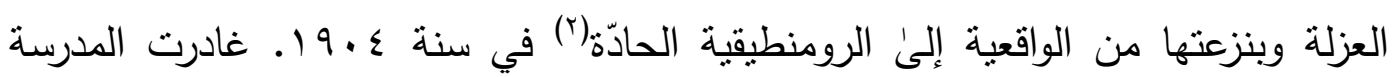
والتحقت بذويها، ثم انتقلت معهم إلى مصر ، حيث تولئ أبوها إدارة مجلة 》المحروسةه وحيث تابعت هي تحصيلها الثقافي والأدبي. وقد قوي ميلها إلى اللغة العربية فاخذت تروض إلى عليها ملكتها الإنشائية، وتستعين على اتقانها بالمطالعة واستماع المحاضرات وكان ميلها الىُ العزلة والتأمل لايزداد إلا رسوخا وشدة،كما كانت رغبتها في تعلّم اللغات تتجاوز كل حدّ، وقد أحسنت تسع لغات أوروبية فهماً وكتابةً منها الفرنسية والانكليزية والألمانية

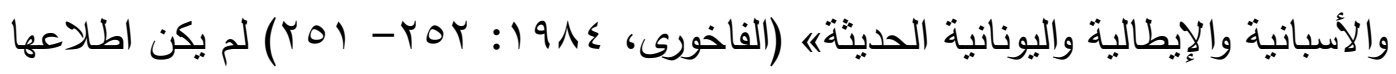
على عدة ثقافات أجنية ليصرفها عن تقدير وطنها ووعي تاريخه ومعنويته، والعشق والإنجذاب والهيام لطبيعته، ومصافاة رجاله من ذوي العلم والأدب، والثقة الراسخة بمستقبله والاهتمام الصادق لمصالحه الاجتماعية وثروته الأدبية. فأصبحت ثللك العواطف النبيلة موضوع كتاباتها وتحريضاتها، تقف لها ما وُهبته من ذكاء راجح، وعاطفة رقيقة، وأندفاع صادق. وما لبثت أن اتّعت عاطفتها الوطنية، فشملت الثرق على اختلاف نزعاته الوطنية والدينية وارتقت إلى العاطفة الانسانية الثاملة، على نور ثقافة واسعة، و رأفة بالإنسانية المزريةه (المصدر نفسه: (Y0). كانت مي من اكثر الناس مطالعة وطالعت حياة الفحول المفكرين والرموز الأدبيين والشعراء الكبار من أمثال دانتي، وشكسبير، وغوتي ،ولامرتين، وهوغو، وشيللر ، وبيرون ، والمعريّ والمتببيّ. وبجانب هذا، طالعت الموسوعات الأدبية منل ونل الأغاني، والعقد الفربد، وآثار الأدباء المتأخرين نظير شبلي شميل، وبعقوب صروف ،وخليل مطران وحافظ إبراهيم. طالعت متحرّية آثار الثهيرات من النساء المفكرات الأديبات كجورج ساند، ومدام دي ستال ، وملك حفني ناصف، وعائشة التيمورية، ووردة البازجي. تتقلت مي في حياتها كثيرا من ناصرة إلى لبنان ومنها إلى' مصر وثم إلى لبنان وأسفارها إلى البلاد الأوروبية أيضاً. والحياة في هذه البيئات المتعددة ساعدت في إثراء تجاربها الفكرية والثقافية ومزجت حياتها بالأدباء والمفكرين في الأوساط الأدبية خاصة في منتداها الأدبيّ الثخصيّ، بينما لم تتس حياة الناس ومسؤوليتها لإصلاحها،إنها في الحقيقة كاتبة اجتماعيّة(؟). كانت 
مخلصة لقضية أبناء بـادها وقطعت أثواطاً في الحضارة الجديدة ولم تغفل أنها شرقية ولها نفسية ومقومات شخصية خاصة تساعدها في العناية بالواقع الاجتماعي • عندما تعرّفت بجبران وعثقته وعرفت آثاره وقرأتها بتمحيص، توقد حبها الرومنسيّ ومالت أكثز من قبل بال إلى الرومنسيّة(؟) جدير بالذكر خيبتها في الواقع الاجتماعي حرّضتها على الرومنطيقية وعلى آراء جبران يوماً بعد يوم.

\section{جنوح مي زيادة إلى' الواقعية ورغبتها عنها:}

جرّبت مي واقع الحياة في حداثثها وحاولت كثيرا لإصلاح ظروف البيئة الفرديّة

والاجتماعيّة وفي كل محاولاتها شعرت بالخيبة ، والروادع الكثيرة والطرق المسدودة . ״الواقعية مذهب يجعل للواقع المادي الدور الاول، ويقول بحقيقة الانسان في ذاته مستقلاً

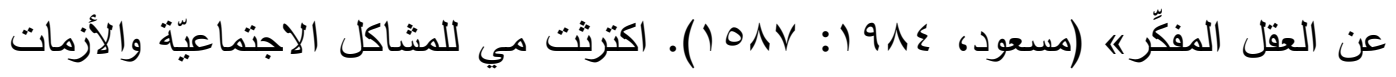
السياسيّة والفكريّة في مجتمعها وسائر المجتمعات البشربة غير أنها واجهت في كل مرة بالنكسة والخيبة والطريق المسدود. اأنتاقُ إلى الموت في هذه الأيام لأني لا أفهم الحياة التي يقول مرشدنا الروحي:»إنها مشكلة المشاكله ونتُهي تصوير حالتها النفسية بالنسبة لمشاكل عصرها وبيتها بهذه الكلمات: كيف أتخلص من شعوري؟ كيف أفنيه؟ كيف أصبر صخرة؟ حدّثني أيتها الحجارة العسيرة،كيف صرت حجارة؟ كانت مي تتفرد بشعور مرهف وحساسية نادرة وغير عادية بالنسبة لما ترى حولها في الواقع الإجتماعي من المظالم والمآسي الداخلية والخارجية. لها اندفاع عفوي للمأساة الكبرى' التي تلت بعد نكبة الأرض بله المقدسة و احتلالها القد شهدنا أثناء إقامتها في أُورشليم كثيراً من المآسي التى كانت تبعث عليها العصبيات والمنازعات الدينية المحتدمة، وتسلك في احتدامها العديد من السبل الملتوية غير المتزنة وكان ثمّة وجوه شبه متشعبة على وتيرة واحدة من الكآبة وتصدر عن مصدر واحد، هو الغلو في الأنانيةه(شراره، 970 1: 7 1). دخلت مي في القضايا الاجتماعية والسياسية والنشاطات التي دلّت على التزام الأديبة بقضايا جماهير الناس والثعور بمسؤوليتها أمام رعايا المجتمع الأنساني وخاصة العربيّ. كما قيل لبأنّ الواقعية مذهب أدبي يعتمد على الواقع، ويُعنى بتصوير أحوال المجتمعه (انيس والزماء،، جr، : انتهجت مي هذا المذهب في بدايات نشاطاتها الأدبية واعتتت بتصوير ظروف المجتمع غير الملائمة للحياة الكريمة الحرّة. نشطت في المجال الصحفيّ وعملت برسالتها في هذا الميدان الاجتماعي، كما ذُكر اسمها بين الصحفيات والكاتبات الاجتماعيات (المقدي ،

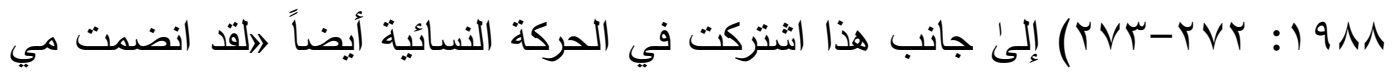
إلى الحركة النسائية التي كانت هُدى' شعراوي على رأسها. وأُشتركت في الاجتماعات التي هي كانت تعقد في الجامعة المصرية القديمة، وكانت أبداً وفيّة لاختها المرأة ،فكتبت عن 
شهيرات النساء في عصرها، فقالت للرجال:»ظلّّوا عاملين تحرير المرأة، التحرير المنشود حتى تسمعوا من نفوسكم تلك الثهادة البديعة،أيها الرجل لقد أحسنت ـ أحسنت لأنك كفّرت،

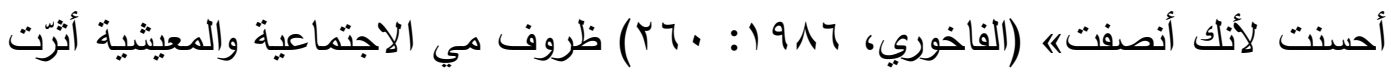
في نزعتها »إذ من المعلوم أن الحوادث السياسية والاجتماعية والدينية التي طرأت على حياة العرب قد غيّرت من روح الشعر وأساليبه وآفاقه، فنرى الرفاهية والحرمان من الاسهام في الحياة السياسية العامة تقودان الحجازبين إلى غزل ماجن عفيف، مختلف المعاني عما عهده الجاهليون و نرى الثعر السياسي يظهر في العراق وتتخذه الأحزاب السياسية والفرق الدينية من وسائل جهدها، كما أن تتظيم الدولة السياسي وتركيز السلطة قد نمّى المدح حتى كاد يسيطر على غيره من فنون الثعر / (مندور، 997 ( 190 إنّها مي دفاعاً عن المرأة وبيانا لتأثيرها الاجتماعى تقول: «المتهكمون على المرأة كثيرون في هذا العصر الفوضويّ ولكن أنصارها اكثر وهم من ذوي النفوس الكبيرة والرؤوس المفكّرة. بل هم أسمى وأثرف رجال زماننا. إنهم بحترمون جهادها، وبعترفون بحقوقها، ويقرون بما تأنيه من الإصلاحات الباهرة ويعجبون باقدامها وثباتها ويرون في نهضتها أبادي جديدة عاملة لخير الإنسانية وتخفيف الويلات عنهاه (شراره، 970 (: بr ( ) كتبت مي مقالات كثيرة عن الحركة النسائية في 》المحروسة《 تحدثت عن قضايا المرأة ونقدت على شكل ما، حرية المرأة المزيفة التى تتجم عن أسرها في أثكالها الجديدةه والكتّاب الذين ناشدوا الاصلاح مافنئوا يكتبون ويخطبون، وكلهم يريدون المرأة حرة راضية ذات شخصية قائمة بنفسها تفرح بنور الثمس، تثمتع بمسرات العلم مدركة من الحياة غير القشرة

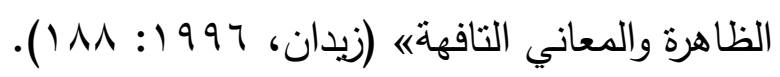
اعترضت مي على الرجال الذين يخافون من كمال المرأة وكسبها العلم والتربية

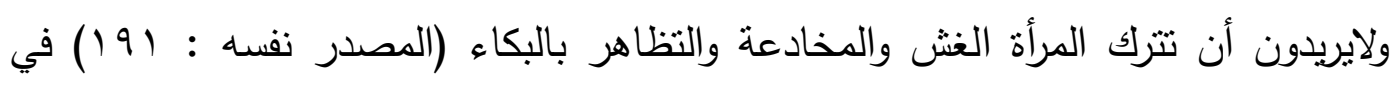
الواقع حاولت الأديبة، دي أن تضطلع بمهنها الانسانية وأن تقوم بوظيفتها الأدبية في العناية بالواقع الاجتماعي ونقله وتصويره للسامعين والمخاطبين،كما إتبع هذا الاتجاه الذين

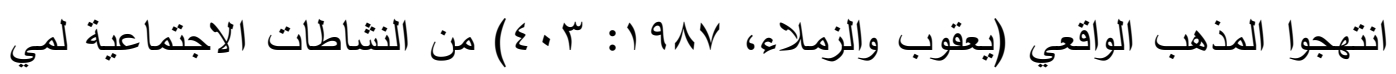
يمكن الاثنارة إلى صالونها الأدبي الذي عُدّ في عصرها إلى جانب النشاط الأدبي، نشاطا اجتماعيا ورابطة فكرية أثرت في الأدب والسياسة والاجتماع أيضاً. كان يؤلف اجتماع الادباء في ثناثاء كل أسبوع ويشترك فيه: يعقوب صروف، ومنصور فهمي، وعباس العقاد ، واحمد شوقي، وطه حسين ، وخليل مطران و ... ( شراره، 970 (: با7) نشاطات الأديبة في

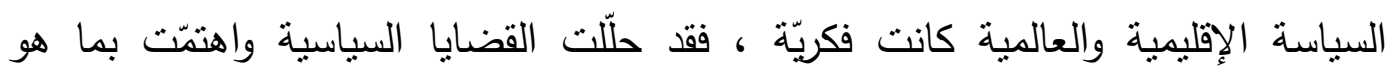
مصلحة لقومها وأمتها. 》 في ميدان السياسة العالمية نجد الأديبة مي تتخذ موقفا واضحا من 
ألمانيا خلال الحرب العالمية الأولى كما يتضح مثلاً من يومياتها: إنّى منذ إثهار الحرب أتحاثى كل ما هو ألماني من مؤلَّات وموسيقى وفنون. إن ألمانيا التى تدوس حقوق الضعفاء، وتتبختز على الأقوياء، وتقتلك بالأطهار، والأبرياء، ألمانيا الضخمة التى تحاول هدم مدنية شيّدتها مدنيات لاتستحق أن تكرم الآن بأفرادها، مهما كان أولئك الأفراد عظماء

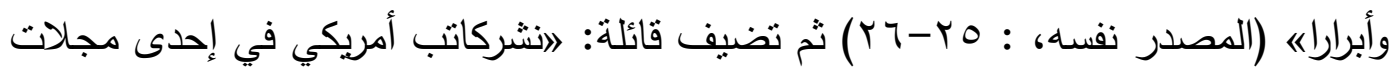
وطنه يقول فيه: إن العلم لم يزد الألمان إلا وقاحة وخشونة وهمجيّة، لأنهم قوم فاقدون للغريزة الاجتماعية، فلذلك لم يهتموا في ارتقائهم إلاّ بالاستعداد لقهر الثعوب (المصدر نفسه : (9). كانت الأديبة مي، مفكرة ومبدعة في تأملاتها، فقد رفضت الخرافات في المجتمع الديني (المسيحي) باسم القضاء والقدر (المصدر نفسه: بع-7ء) وفي مجتمعها كذالك رَفْضُها للخرافات يعدُّ نوعا من الجرأة وطلب الحرية الفكرية. بعد تأملات ودراسات ملفتة للنظر وصلت إلى الفكرة، بأن القرآن هو الدليل الاساسي والمحوري لبقاء اللغة العربية حيّة نشيطة طول تاريخها (شراره، 970 (1: ع 1 ) أنها صرّحت بتأثرها الثديد بالقرآن في أسلوبه وقراءته. رغم أنها كانت مسيحيّة لاتتعصب لدينها وأستفادت بالحرية الكاملة من القرآن وهذا ينمّ عن حريتها الصادقة وانفتاحها الاجتماعي الأصيل. إلى جانب اجتماعياتها التي أثرنا إلبها، تطرّقت إلى \الطيقيّة، والأرسطقراطيّة ، والعبوديّة، والديمقراطيّة، والاشتراكيّة وغيرها من التيارات والنظريات وتبيّن إخفاقها بتحقيق المساواة وذلك بأسلوب علمي دقيق، وبجولات واسعة في تاريخ الثعوب وفلسفاتها، وبنظر بعيد عن النطرّف والمغاليات (الفاخوري،

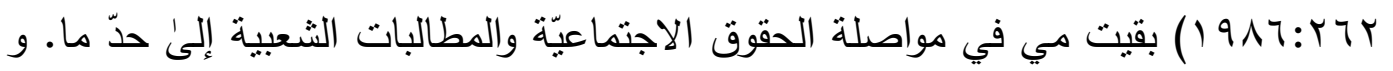
في المراحل التالية من حياتها تتازلت عن المسائل الاجتماعية وجنحت متطرفة إلى' عالم الخيال أو الرومنطيقيّة وتركت الثّارع أوْ بتعبير آخر هربت من القضايا الاجتماعية لمواجتها بالخيبة والنكسة .

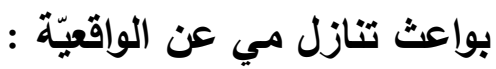

لم يأت في أيّ كتاب ومقاله موضوع تتازلها عن القضايا الاجتماعية الواقعية وبواعثها بالصراحة، غير أنها اتجهت الى الرومنطيقية ، بعد ما جرّبت الواقعيّة وهذا واضح وضوح الثمس • ولكن من خلا دراستنا وبحثنا في المصادر المختصة ، وصلنا إلى' نتائج مرغوبة واستتبطنا تتازلها هذا، من دراسة المصادر المعنية بهذا الموضوع: 1 - كل انسان مفكّر ورساليّ له طموحات وآمال سامية بحاول تحقيقها، بيد أنها القضايا السياسية والاجتماعية في عرضة الانتصار والانكسار والأمل والخيبة، خاصة المفكرّ غير المجرب في الميادين السياسية العملية الذي يخاف من مواجهة الأخطار • نفسه الشعور بالخوف والهيبة يقترن بالخيبة ويؤدي اليها لقُرِت الهيبة بالخيبةه (نهج البلاغه، قصار 
الحكم: (Y) بينما لا يستطيع مرهفو الشعور البقاء في ميدان المعارك الاجتماعية، واذا بطريق مسدود بشعرون ويتوققون عن الحركة. كانت مي قد واجهت صعوبات عظيمة و روادع منيعة لم تتحمل الدوام والبقاء في هذه الظروف وهذا طبيعي الىُ حدّ ما، لأنها تلقّت ضربات طاحنة ولم تقدر مكابدة القضايا الاجتماعية الواقعية اكثر منهاء(ه). r- حياة مي كانت منتقلة وكثيرة الأسفار وشديدة المشاكل وهذا ما هَبََّّ أرضية مناسبة للانصراف من الواقعية والميل إلى الرومنطيقية. أرادت أن تقلل المشاكل التى كابدتها كل يوم ولهذا لاذت بالأجواء الفكرية الرومنطيقية الخياليّة(؟). r- كونها ملتزمة بشعبها وقضاياه وعدم التقدم الملحوظ في طموحاتها عمليّا والخيبة

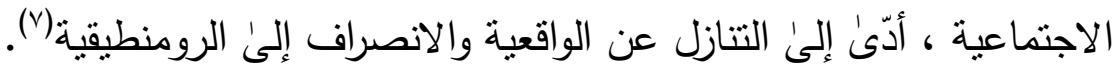
ع- أنوثتها ورهافة حسّها الطبيعي الأصبل وعيشها قلقة ومعذبة ومُرزية ونكستها في حبّها الطويل المستمر، تعد من عوامل رغبتها عن الواقعية والميل إلى الرومنطيقية أوْ عالم

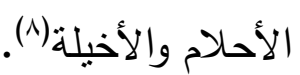
ه- كونها لبنانية الأصل والتأثر من الجوّ الفكري والطبيعي الخاص وأجواء فكرية مصرية امتلأت بتجارب الماضي والارضية المناسبة إلى السفر الخيالي التاريخي إلى ماضيها، كانت مؤثزة في هذه العمليّة(9). צ- مرارة الأيام وموت الأب والأم وحبيبها جبران خليل جبران، أثرّت مباشرة في أخلاقها وميلها الثديد إلى' التقرد والانزواء والهمس والنجوى' ('). - - ميلها الفردي إلى الخيال والتفرد المعيثي وظروف البيت وكونها وحيدة في اكثر

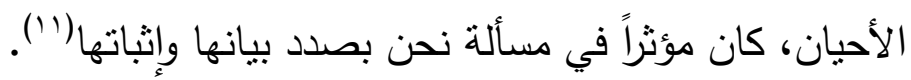
1- إنها احبّت جبران وأحبّها أيضاً وقراءة آثناره ورسائله الرومنطيقية وأمنزاجها بحبها جعلتها منتأثزة بجبران و قلمه السحريّ الرومنطيقيّ . رومنطيقية مي ومعالمها الواضحة أنموذجاً: الرومنطيقيّة والرومنسيّة والإبداعيّة والرومنتيكيّة ألفاظ مستخدمة في النقدية العربية كلها تعني تيّارا أدبيا ظهر في انكلترة وألمانيا في القرن الثامن عشر وأهم ميزاته: طلب الحرية والإغراق في الغنائية وتقديم الخيال على العقل (يعقوب: 9 (ب) والرومنطيقية اتجاه فنيّ في الأدب يمتاز أساساً بطغيان العاطفة على ما عداها من مقومات ، والقول هنا بطغيان العاطفة يعني تفجّر الأحاسيس والمشاعر وتماديها بحيث يغرق في لججها الصاخبة كل تفكيرعقليّ منطقيّ وبحيث يصبح الخيال المشعوذ والملتهب في خدمة الغرض العاطفيّ بدلا

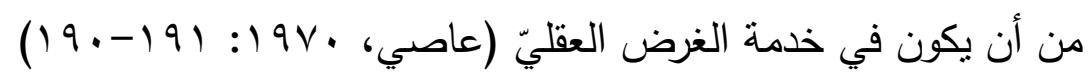


\اختلفت الأقوال في نسبة اللفظة وأنثتقاقها اللغويّ. ولكنها على الأرجح مأخوذة من جذرها الأصلي „Roman«، بمعنى القصة الخيالية الطويلة ، أو إحدى قصص المخاطرة

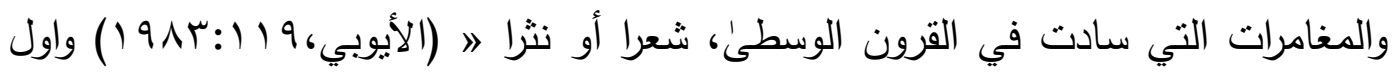
من استخدم 》الرومنطيقية《 في الأدب هو 》فريدريش《 شلغل الذي طرح الشعر الرومنطيقيّ

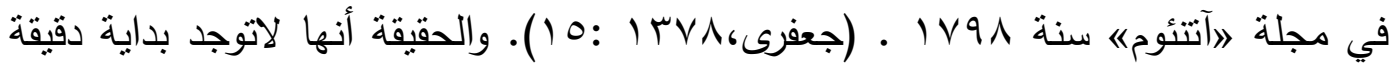
لهذه الحركة 》ليس من السهل معرفة البدايات الحقيقية لحركة الرومنطيقية بالمنظار الزمنيّ. لأننا إذا توغلنا في التأريخ، زلت بنا القدم، دون أن ننتهي إلى' أية نقطة انطلاق والسبب في

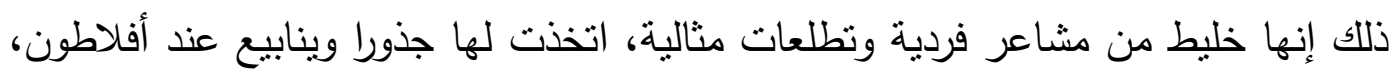
أبي الفلسفة المثالية في تاريخ الفكر البشريّ. هناك عوامل اجتماعية متجذرة في الحياة البشرية من إنسانية واجتماعية وأدبية قد مهّدت لظهورهذا المذهب الذي عرفناه بوضوح وتألّق

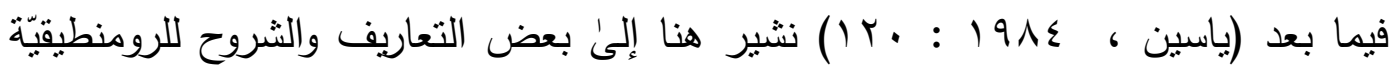
لتظهر مفهومها وبوضوح هي تساعدنا في كثف معالمها عند الأديبة، مي: الالرومنتيكيّة مذهب أدبيّ وفنّي يتميّز بالتعبير عن مشاعر النفس وقوة العاطفة وبُعد الخيال والعودة إلى

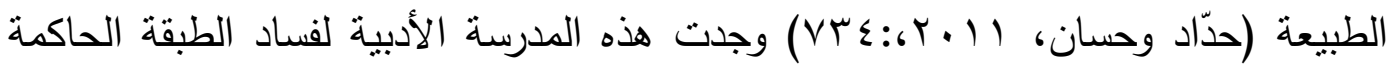
في أروبا وتلاشي الظروف الاقتصادية وعدم اتباع الناس من الحكّام ومخالفتهم للقواعد

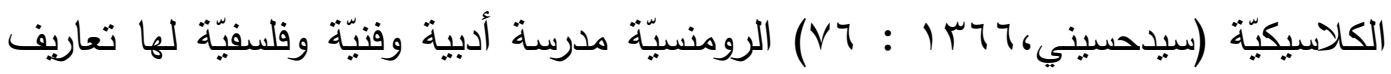
عديدة وهناك تعريف يصرح بأنها فوضى' الخيال والذهن (جعفري، TVA لوكاتش من بُناة علم الاجتماع الأدبيّ: لهل ما أراده الرومنطيقيون كسبه، كفى للموت الجميل فقط، ولم تكن فلسفة حياتهم إلاّ الموت ولايعرفون فنّا إلا فنّ الموته (المصدر نفسه: بr) يمكن القول في هذا المجال،ان المدارس الأدبية في صلتها مع الأخرى' كالمجرّة أو قوس القُزح. الالوان مستقلة في النظرة الأولى و منتابكة عند رؤية دقيقة في الوقت نفسه . الشعراء الكبار والرّواد في نزعاتهم ليسوا خارجين عن هذه القاعدة. هم يستقلون في نزعاتهم الأدبية، بينما مناهجهم وأساليبهم ومضامينهم مشتبكة. عناوين مذاهب الشعراء والأدباء واتجاهاتهم خاصة ولكنهم يمزجون أساليب المذاهب في أعمالهم الأدبية ولايمكن فصلها عن الأخرى بشكل كامل. كانت مي واقعية النزعة وتتازلت عنها ومالت إلى الرومنطيقية وعوامل جنوحها إليها هي نفس العوامل التى أثيرت في بواعث تتازلها عن الواقعية. بعض التض الانتقادات الموجهة إلى الرومنطيقية مثل تعاظم الأدباء والتعبير عن أنفسهم وتعريفها، كما عمل جبران في كتابه "النبيّ" واردة وصحيحة،ققد دعا نفسه نبيّا ردزيّا ومصطفى في الكتاب هذا، ليس إلا جبران ولايربد شخصا آخر. سُمّى عصر الرومنطيقية، عصر الأنبياء الكاذبين! ويُراد بالتعبير هذا، الأدباء الذين جعلوا أنفسهم في مكانة الأنبياء! في إرشاد الناس 
ودعوتهم إلى الصلاح. رغم هذا الواقع غير المرغوب اتجهت مي إلى جانب المذهب

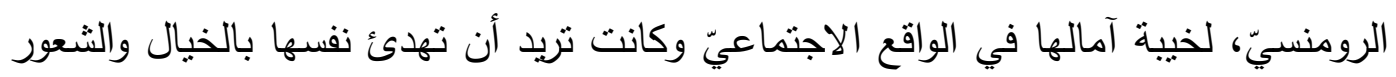

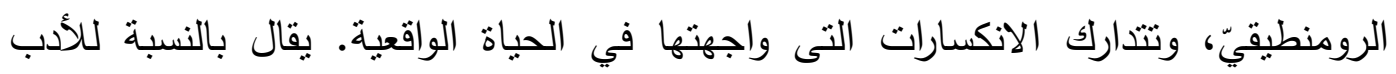

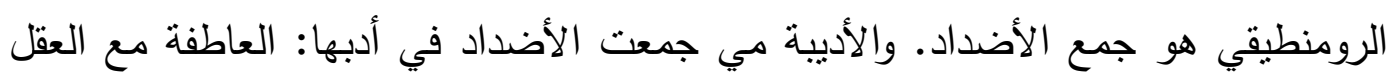

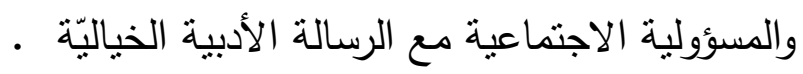

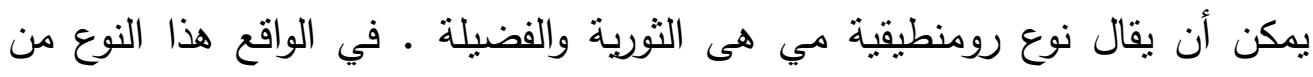

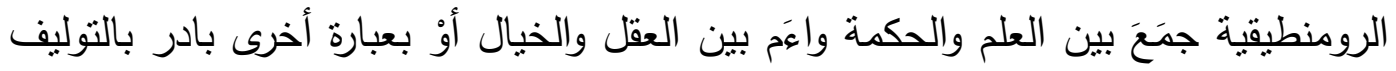
والتلطيف بين المنهجين الضروريين لديمومة حياة البشر. قيل ان الرومنطيقية خمدت

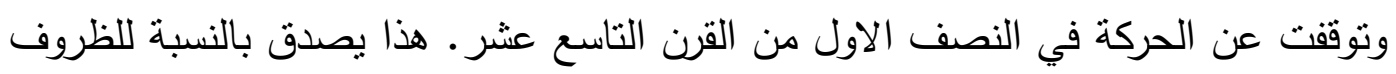
الأدبية الأوروبية، واستمرت في البلاد العربية خاصة لدى مهاجري العرب في في القان القارة

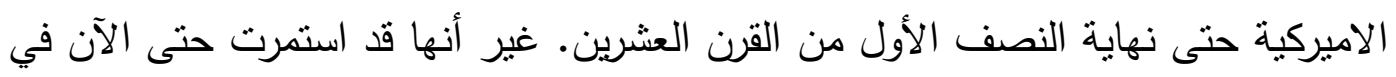

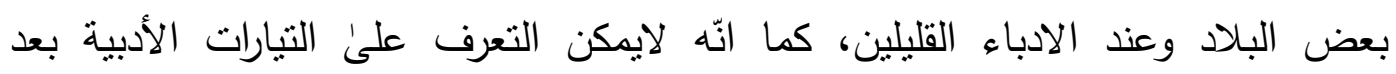

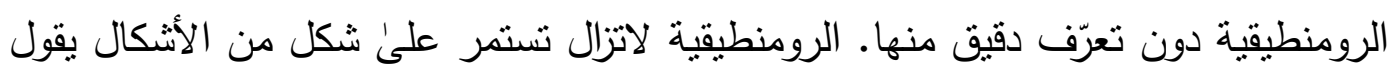

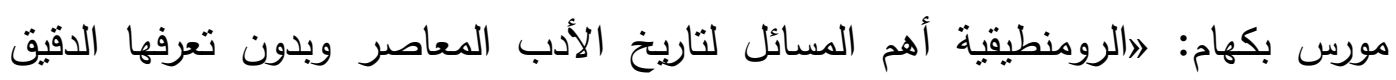

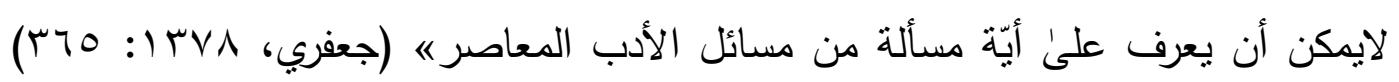

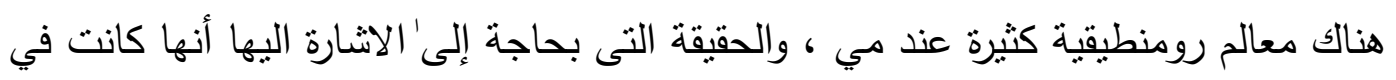

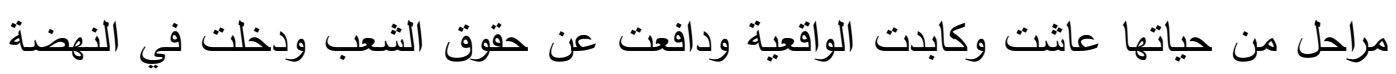

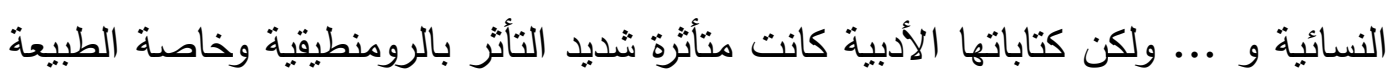

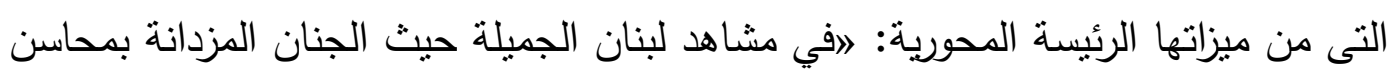

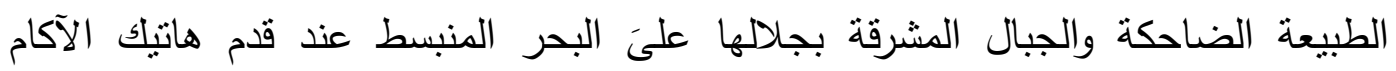

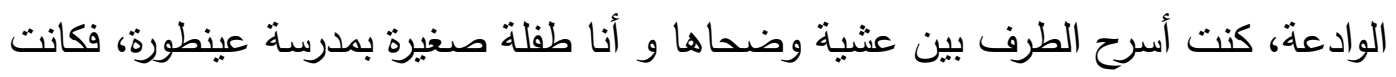

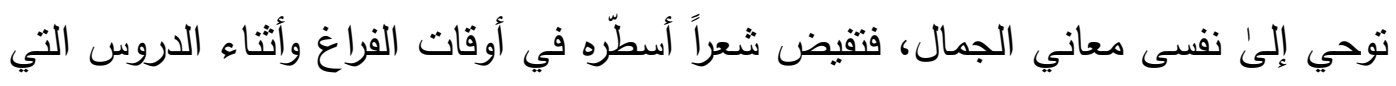
كنت أشتغل عنها بنظم الثعر وتدوينه حتى اجتمع لي منه مجموعة باللغة الفرنسية

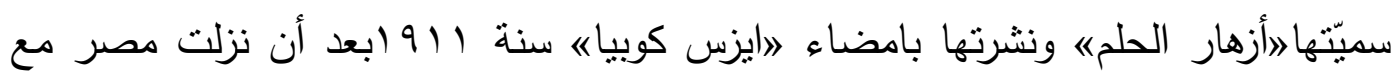
والدي. وكانت هذه المجموعة أول كتاب صدر لي في عالم التأليفه (زيدان، 997 إ:

(rto

"Romantic Poetry has always been closely realated to nature, and it has most of the time been calld nature poetry (Haghighi, 1993, P 43) وكما رأينا فإن الأدب الرومنطيقيّ يعدٌ أدبا وشعرا طبيعيا أو ممزوجا بالطبيعة اطائر

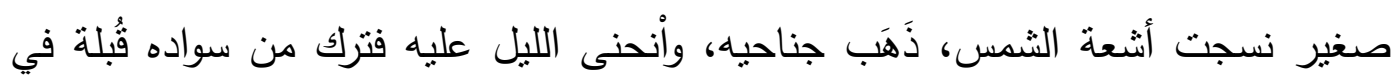

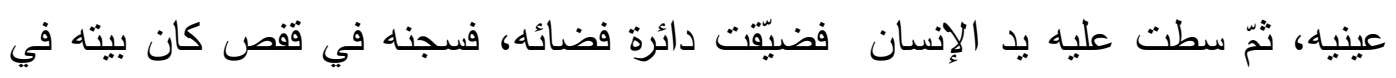




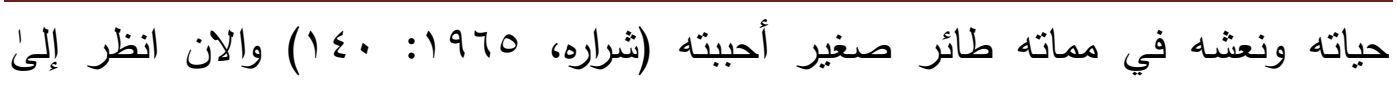

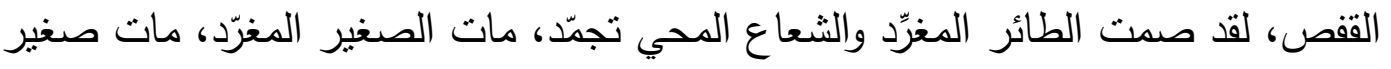

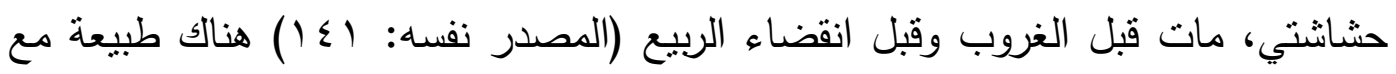

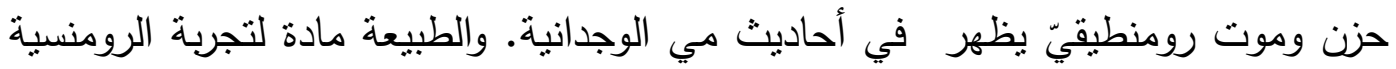

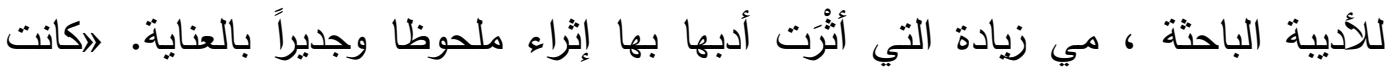

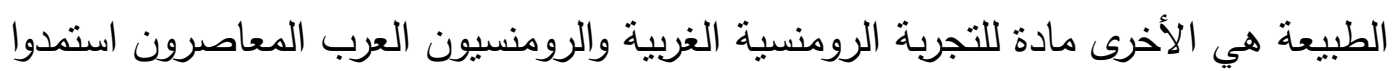

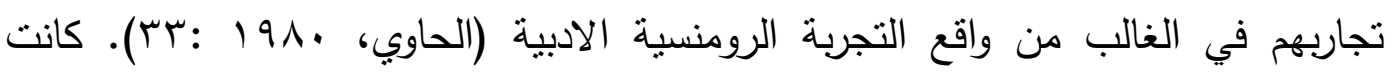

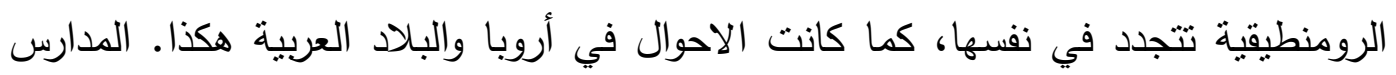

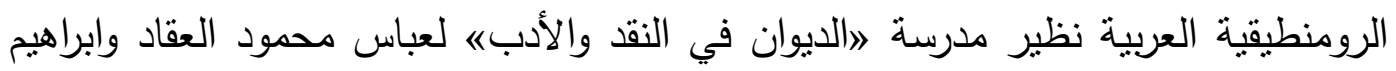

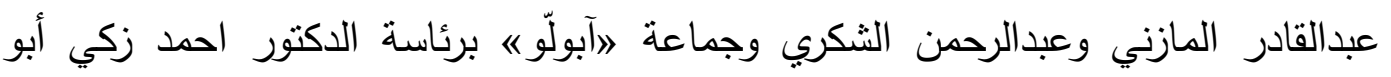

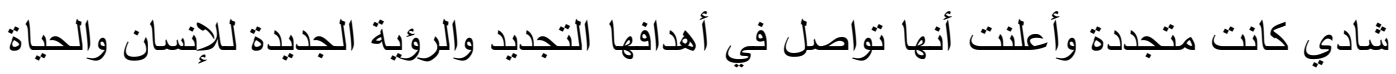

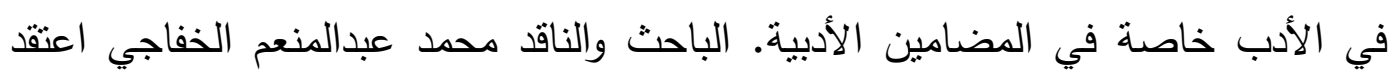

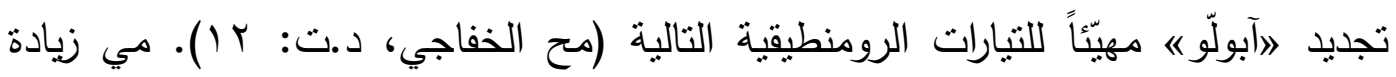

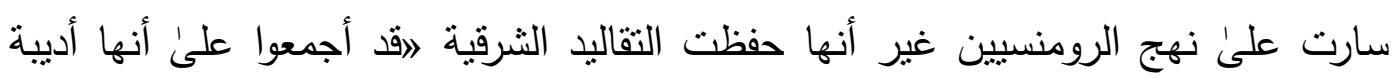
مرهفة الثعور، رومنطيقية النزعة وامرأة متصسكة بالثقاليد الثرقية، تحررّت فكريا ولكنّها

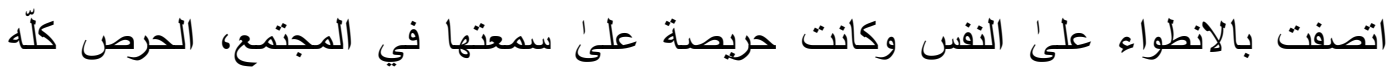

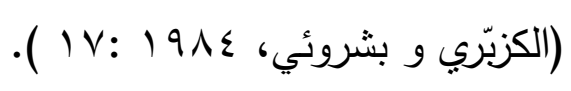

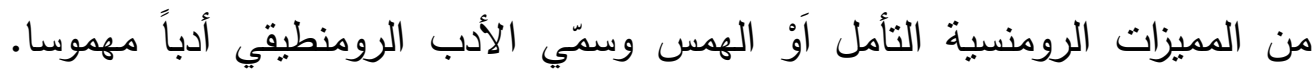

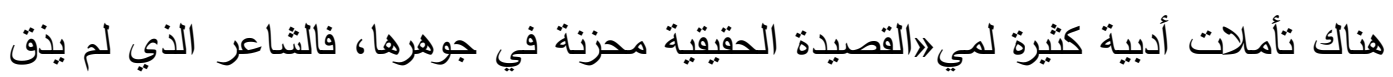

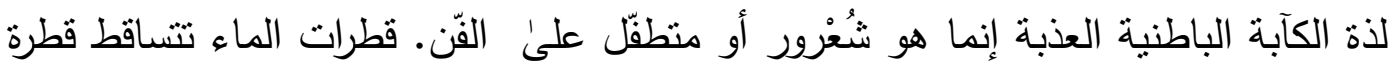

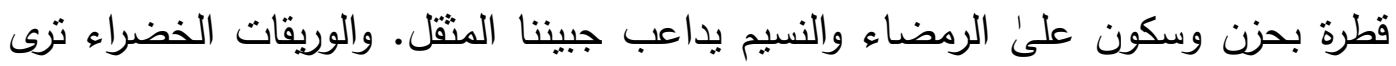

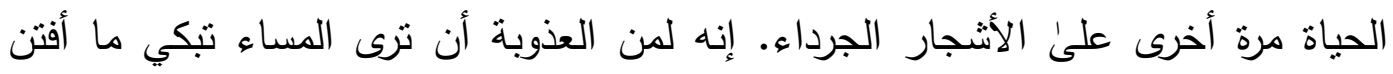

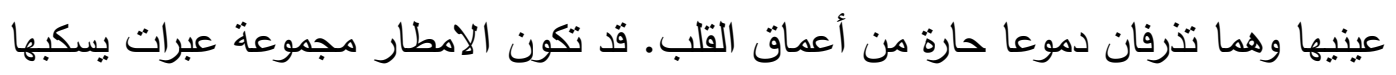

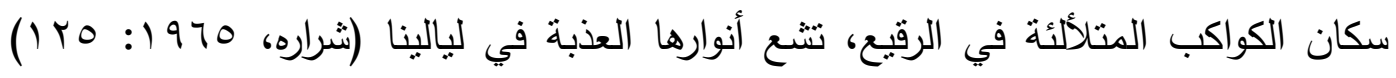

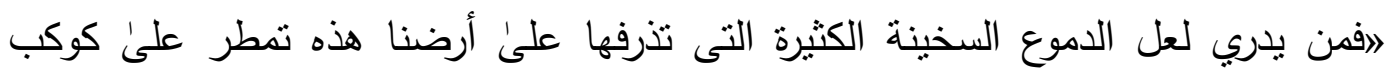

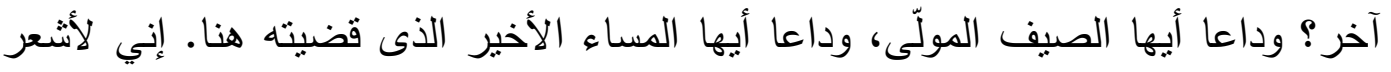

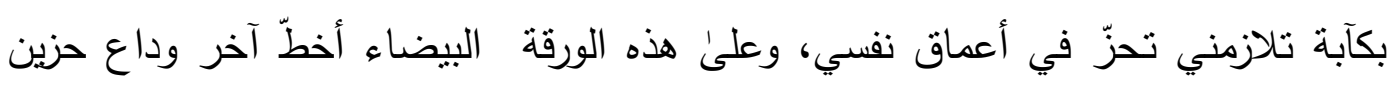

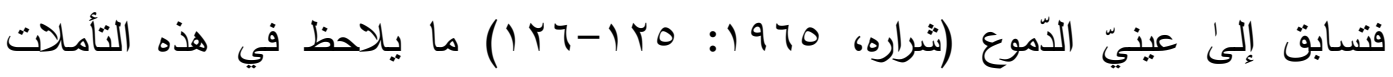

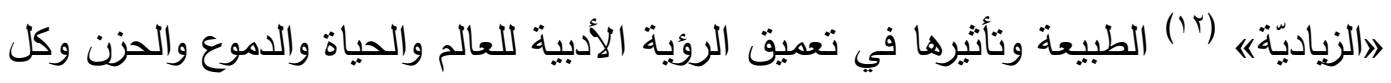

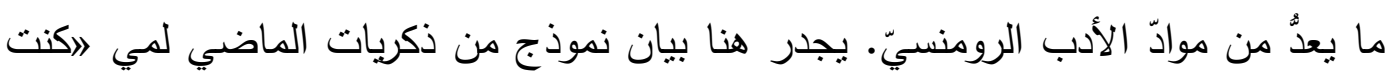


أراجع هذه الذكريات الحيّة وأنا أنظر من نافذة قاعة المائدة الى جبل الكرمل الذي كانت السفينة تدور حوله فُي تلك الساعة، ساعة الظهر • وَدَّعني جاري عند الغروب والزوارق تحتشد حول الباخرة الراسيةه (شراره، 1970 :بr|) الى' جانب هذه، ذكرت مي مدينة ״يافاه كثيراً وادّعت بانّ سفينة نوح (ع) صُنعت فيها! الحبّ:

وإذ نتألم نفس محبة في سبيل نفس محبوبه، ففي ذلك جهاد نبيل مرغوب تقوى فيه

الملكات، وتسمو الميول، وتتنظم النّزعات والرغبات، ويصبح المجاهد عنده بطلا عبقريا على نوع ما، لانه يرمي إلى' ما هو فى نظره جميل عظيم ويخلق الوسائل لتحقيقه (زيدان، 1997: (Y01) كانت في إحدى' رسالاتها إلى جبران الذى يسكن في أميركا، تصرح بأنها تخاف من الحبّ. في رؤيتي إنها واجهت في حياتها بصدمات ومشاكل عديدة وتعود جذور بعضها إلى' حبّها وصداقتها فيها(إنالذين لايتاجرون بمظهر الحب ودعواه في السهرات والمراقص والاجتماعات، ينمّي الحب في أعماقه قوة ديناميّة رهيبة، قد يغبطون الذين يوزعون عواطفه في اللألأ السطحي لانهم لايقاسون ضغط العواطف. أعرف أنك محبوبي، إنّي اخاف الحب إنّي أنتظر من الحب كثثرا فاخاف أن لا يأتنيني بكل ما أنتظر ه (شراره، ه7 197 : Y Y (Y). لأمّا حبّ جبران لمي وهي الأديبة اللبنانية المنبت، الثرقية الروح، فقد كان معادلاً حبّه العارم لوطنه لبنان ولروحانية الشرق ومرتبطا بهما وبالدم العربيّ الذى كان

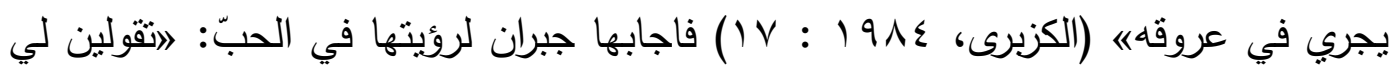
أنّك تخافين الحبّ، لماذا تخافينه با صغيرتي؟ أتخافين نورالشمس؟ أتخافين مدّ البحر؟ أتخافين مجيئ الربيع؟ إعْلَمى أن القليل في الحب لايرضيني، نحن نربد كل شيء، نحن نريد

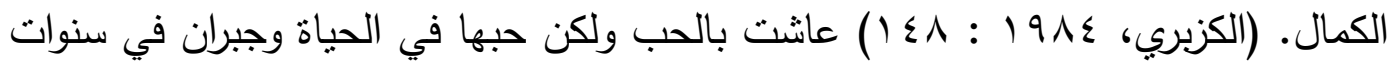
طويلة جعلتها كئيبة متبرمة وفي الواقع هذا يدلّ على م مارسة الحب كثيراً وثورتها العاطفية

التأمل والشكوى' والحزن:

من ميزات الأدباء الرومنطيقين التأمل في الله، والحياة، والانسان، والموت والخلود و ... سائر القضايا التي تتصف بميزة التأمل اَوْ الهمس. لاذا كان جَبر العظام موجعا إلى هذا الحد فكم من قلوب كسيرة لايهتم في جبرها أحد وكم من نفس ممزقة وليس يد راحمة تضمد جراحها ولوبمثل نللك اللمسة القاسيةه (زيدان، 999 ( 199 : 10 ( ))أفت لي، إنىّ خائرة العزم، أنا التي أطلب الموت وأربد أن أتحلّى بالفضيلة والتقوى، ما عرضت لي معاكسة صغيرة التمرد في الكبرياء وحبّ الذات، والغرور النزق، وتحالفت جميع عواطفي الثريرة على هذا الفعل الصغير من أفعال التواضع والتجلد، فاذا بي أشكو وأتذمر وأبكي(شرارة، 970 ( 
لقد احمّرت اوراق الخريف خجلا من قبلته الفاترة إذ عانقها ناجاها بلسان نسميه اللبق الذى يتوانى حزينها ثم يعصف صائحا

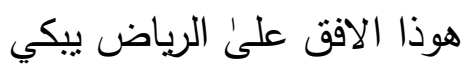

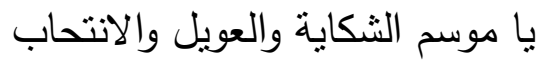
بعد الضحك الذى وانقضى ولن يعود وموسم اليأس الذى يفجع الفؤاد ازاء هدؤ المسافة وجورالزمان

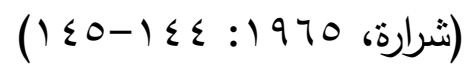
من مميزات الأدب الرومنطيقي، الحزن، والليل، والخريف، والدقبرة، والتشاؤم، واليأس من المستقبل، والنزوع إلىئ الحياة البدوية الطبيعية وتمجيد عصر الطفولة والعودة إليها بالاحلام.

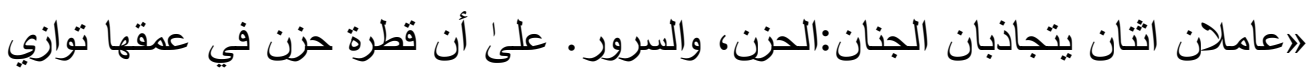

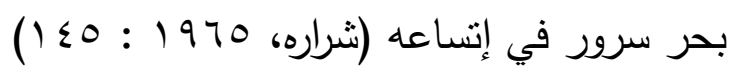

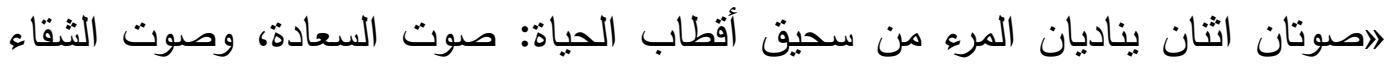

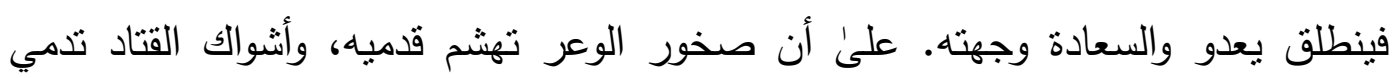

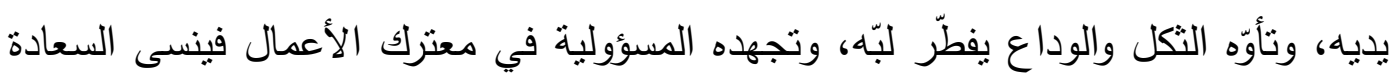

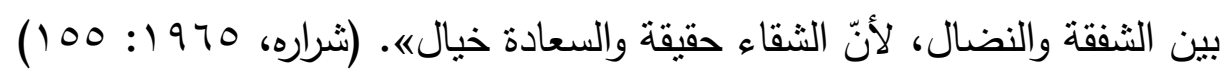
تحن مي إلى الوطن وتعود كثيراً في عالم الاحلام إلىن الحياة الطفولية و مسقط رأسها:

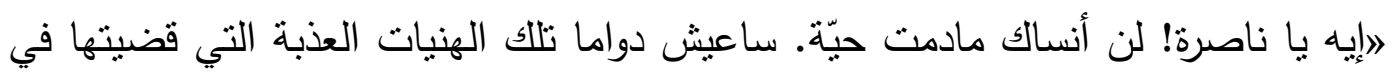

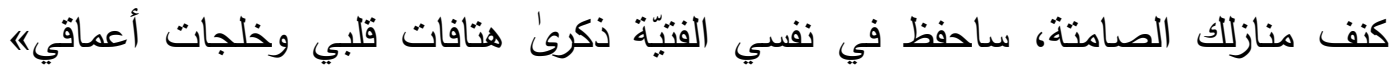

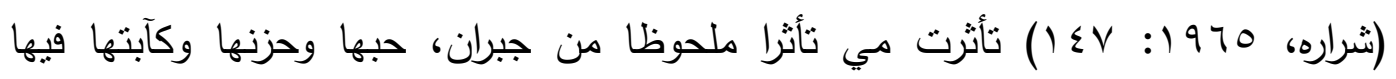

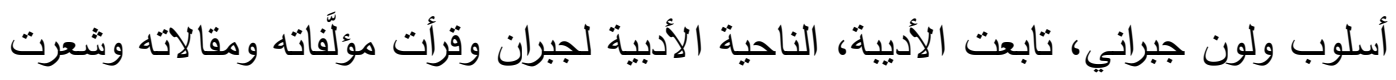
بهذا وبالرسائل المرسلة إليها من جبران من ديار الغربة، إنه قريب من قلبها بالبانية الفكر والخيال

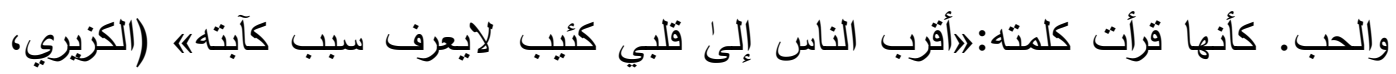
() $\leqslant \vee: 191 \leq$

\section{حبّ الانسانية والرسالة الانسانية أمام الثرق وأبناء نوعها :}

انتتهرت مي بالانسانية ونزعتها في هذا المجال مستمرة ومتواصلة. إكانت مي في إنسانيتها متأثرة بأحمد فارس الثدياق، وجبران خليل جبران، وامين الريحاني ووليّ الدين

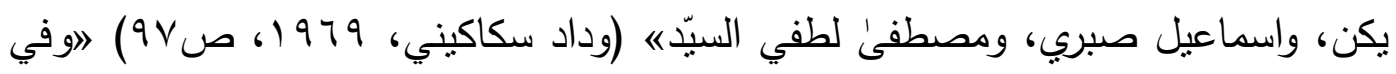

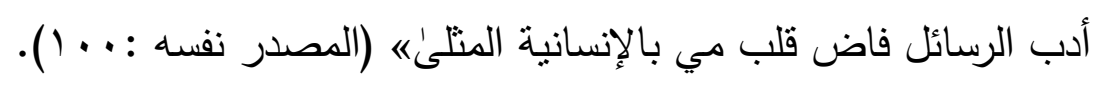


كيفية تصرّف مي للقضية الإنسانية تختلف مع الأدباء خاصة جبران، إنّما مزجتها بالواقعية والرومنسية في الدفاع عن المحرومين واليتامي تقول: 》إنى أنخرع بصوت الإنياء هولاء

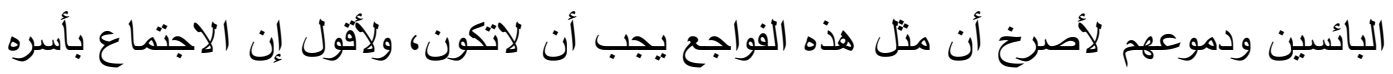

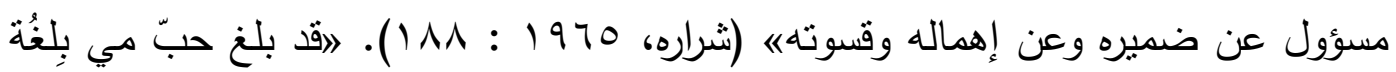
الآباء والجدود والوطن الجديد الذي يعتزّ بشرقيته وتراثه إنها غلت في لغتها ولتها ومقوماتها

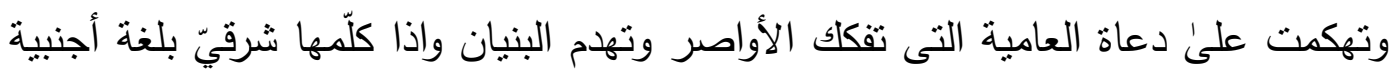

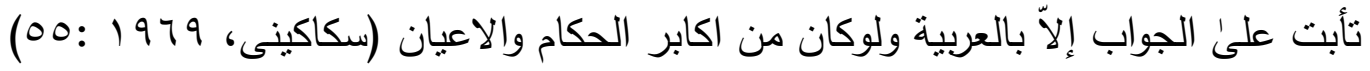

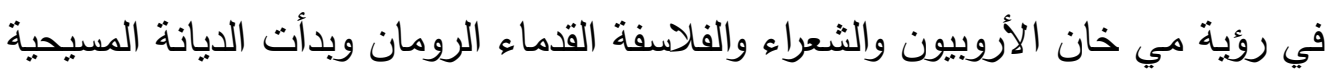

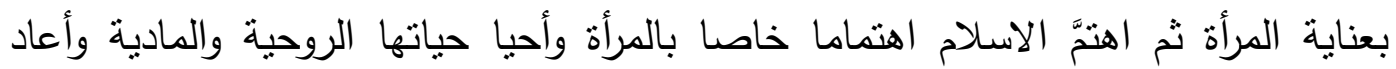

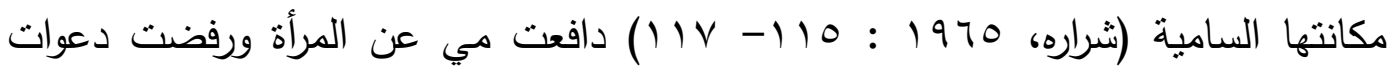

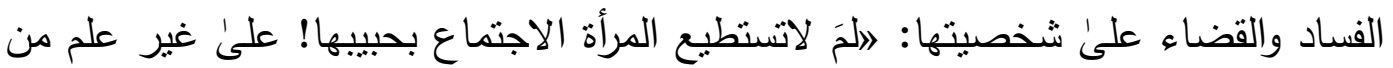

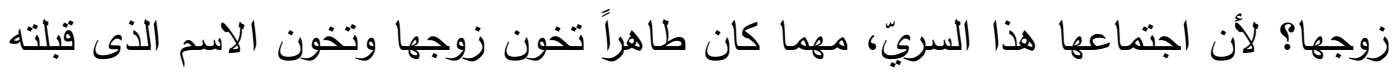

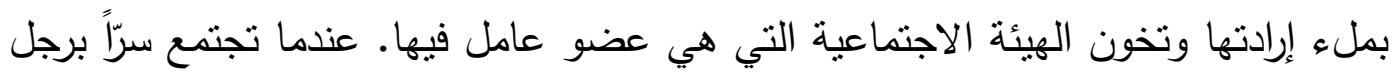
آخر تُعدّ مذنبة إزاء المجتمع والعائلة والواجب عندالزبة الزواج، تُعدّ المرأة بالامانة، والامانة

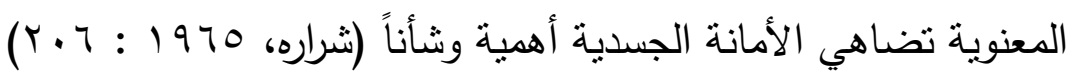

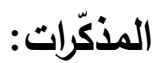

1- مصطلح البرج العاجيّ نحته الثاعر الفرنسيّ سانت بيف ، ومعناه أنّ الأدباء

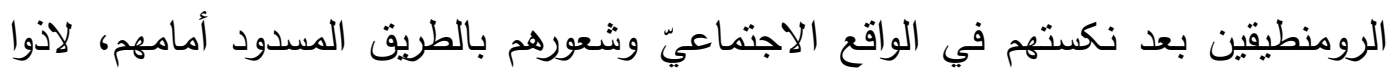

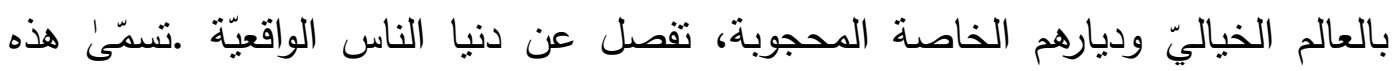
النزعة بالبرج العاجيّ وأدباء هذا التيّار الأدبيّ يسمّون بأدباء الأبراج العاجيّة التيّة

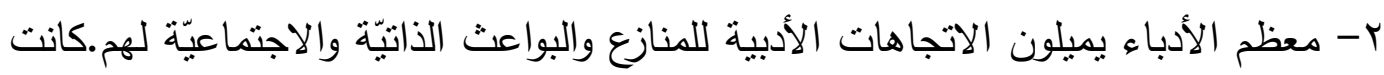

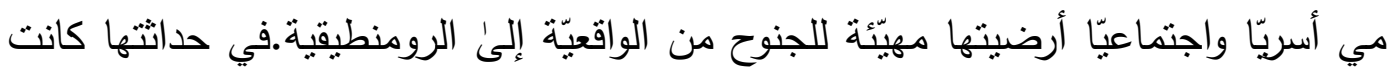

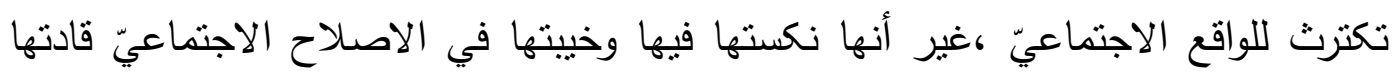

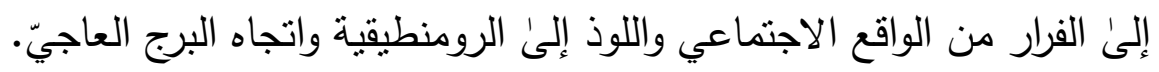

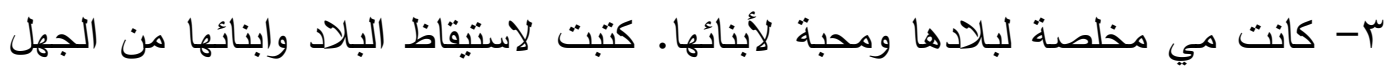

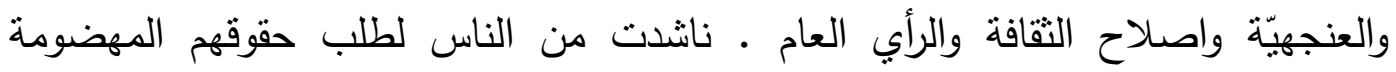

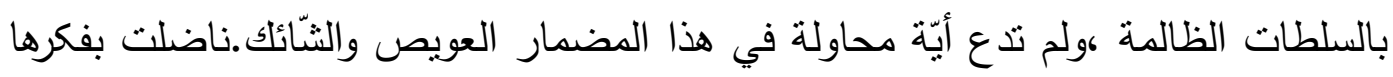

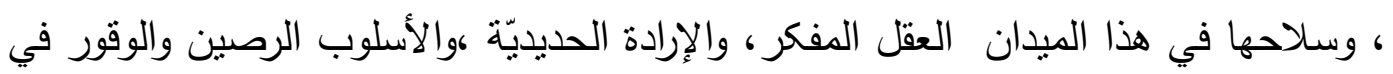
تعبيرها عن منازع الناس ومطالباتهم الاجتماعيّة. 
ع - حكاية رسائل جبران ومي زيادة حكاية شهيرة ـ قصة الشغف والحب العذريّ بينهما من أرفع قصص الحب وأنبلها بين الأديبين.المراسلات الغراميّة والعذربّة أثرّت على مي خاصة في نزعتها الىُ الرومنسيّة.الحب بينها دام زهاء عشرين عاما، ومي لحبها الثديد لجبران نوقد اتجاهها الرومنسيّ. قد أعجبت كثيرا بمقالات جبران وافكاره واسلوب تعبيره الخلاب والمبتكر الذي لا نظير له في اساليب التعبير العربيّة.الحب يدخل في القلب من غير استئذان

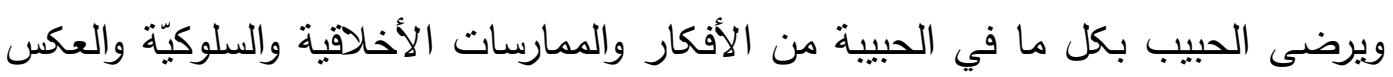
صحيح أيضا. ه- البقاء والمقاومة أمام المشاكل والروادع الاجتماعيّة صعب خاصة للنساء،انها لينة روحيّا ولا تتحمل العنف،والضغط الاجتماعيّ. كانت مي تعتتي بالاجتماعيات إلا انها تركت الثارع وتمسكت بنشر الفكر والعمليّة الفكريّة وتتوير الرأي العام وتوجيه الناس وإرشادهم الىئ حقوقهم ومطالبهم المحقّة . ج- هذه الميزات الخاصة لدى' مي زيادة نظير : كثرة التنقل والسفر وشدة المشاكل والمكابدة بالحياة القاسية كلها ميزات تهيّئ المجال للجنوح إلى الرومنطيقيّة .والأديب الرومنطيقيّ يحمل هذه الظروف أساسا. - Vنوحها إلى الرومنطيقية والتتازل عن الواقعية لا تعني التهرّب من المسؤولية الاجتماعيّة، بل يُعدّ تغيير الاستراتجيّة عملا بمهنتها الانسانيّة ومهمتها في تتوير الرأى العام

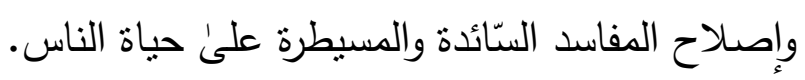
1- الأنوثثة ورهافة الحس والعيش القلق والحب الطويل والمعذّب مع جبران لأكثر من عشرين عاما وداء البعد والفراق سبّبت أن تميل الأديبة دي إلى الأحلام والأخيلة الرومنطيقية.

9- إنها عاشت في لبنان والأجواء الفكريّة اللبنانيّة المناسبة تاريخيا للمذهب الرومنطيقيّ منل الجو الطبيعيّ الجميل ، وتجارب الماضي وميلها للسفر الخياليّ في ذكرياتها الماضية كانت مؤثزة في جنوحها إلى الفكرة الرومنطقية. • 1- صعوبة حياة مي ، وموت ابيها،وموت حبيبها جبران وعاشقها لاكثر من عشرين سنة

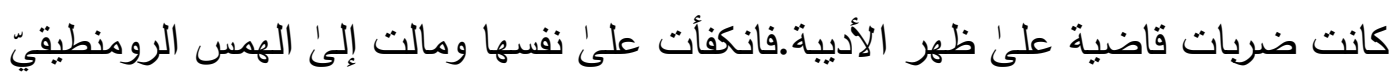
والنجوى'. 11 - مي زيادة تميل فرديا إلى التقرد والانكفاء المعيشي وهذا يُعدّ نوعا من الهمس .والأدب المهوس أحد مصاديق الأدب الرومنطيقيّ .علاوة إلى هذه المسائل ،ظروف البيت وصفاته الوراثيّة كانت مؤثرة في ميلها إلى المذهب الرومنطيقيّ.

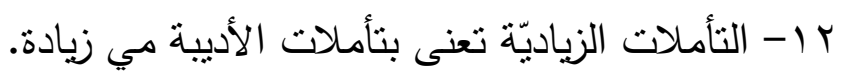


النتائج : نتائج المقالة هذه كما يأتي على الترتيب الرقميّ:

1- كانت مي في بدايات حياتها العلمية والأدبية خلال حداثة سنّها واقعية النزعة، لأنها: النها تتعر برسالة الأدب إلى الإنسانية وخاصة المجتمع العربيّ وانشتركت في القضايا

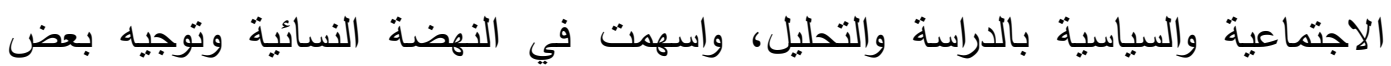

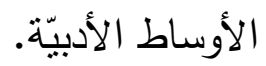

r- نزعت مي إلى الرومنطيقية، بعد ما قضت سنوات في الواقعية والاسهام في ميادينها

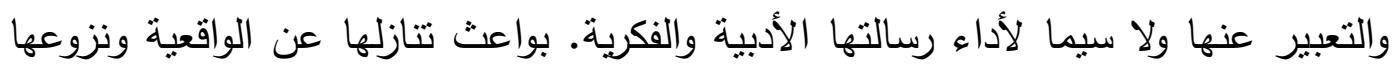

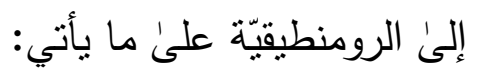
ץ-1 عدم تحمّل الصعوبات الثديدة والمستمرة لزمان أطول في مكابدة الواقع الاجتماعي.

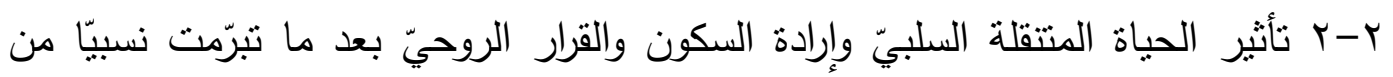
حياتها. r-r أنوثثها ورهافة حسّها هيّأت الأرضية للجنوح الثديد إلى الرومنطيقية وعالم الأحلام

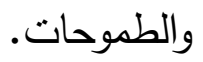
ץ-؛ الثأثرّ من البيئة اللبنانبة والدصرية والانفعال الملحوظ من خلفيات الطفولة في فلسطين. r-ه مرارة الأيام وموت الأهل وحبيبها، أثّرت عليها وخلّفت آثاراً لم يُرفع أثرها السبلي إلّا

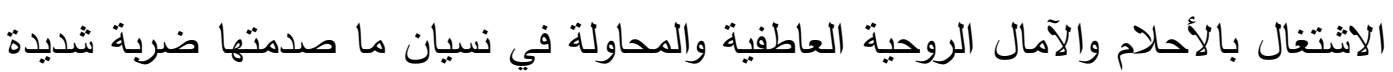
على قلبها الرقيق وحتّها المرهف. ץ-7 الميل الفردي والصفات الثخصية العاطفية التي كانت تدفعها إلى الرومنطقية منذ طفولتها وازدهرت هذه بعد مرحلة الثباب.

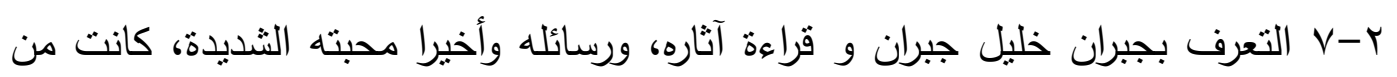
البواعث الأساسية في انصرافها عن الواقعية و الميل الثديد إلى الروانئ الرونطيقية.

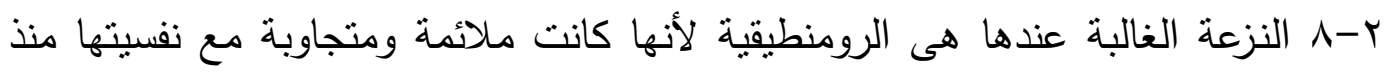

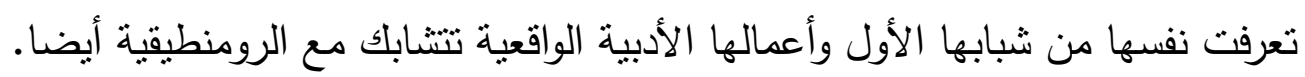
المصادر

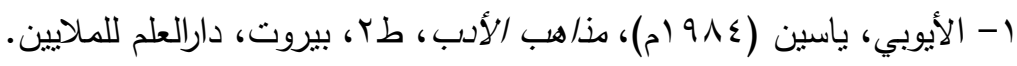

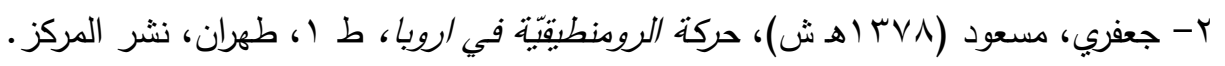

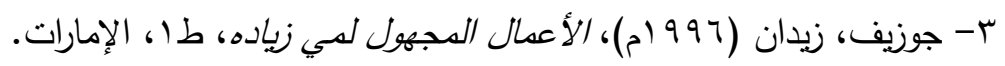

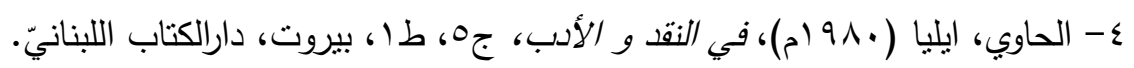

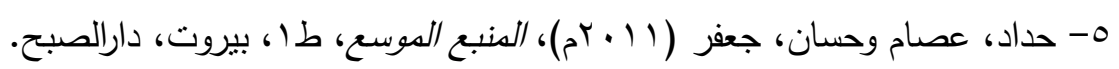
צ- خفاجي، محمدعبدالمنعم (د. ت)، الأدب العربيّ الحديث، جن، جن، قاهره، مكتبة الكليات الأزهرية. 


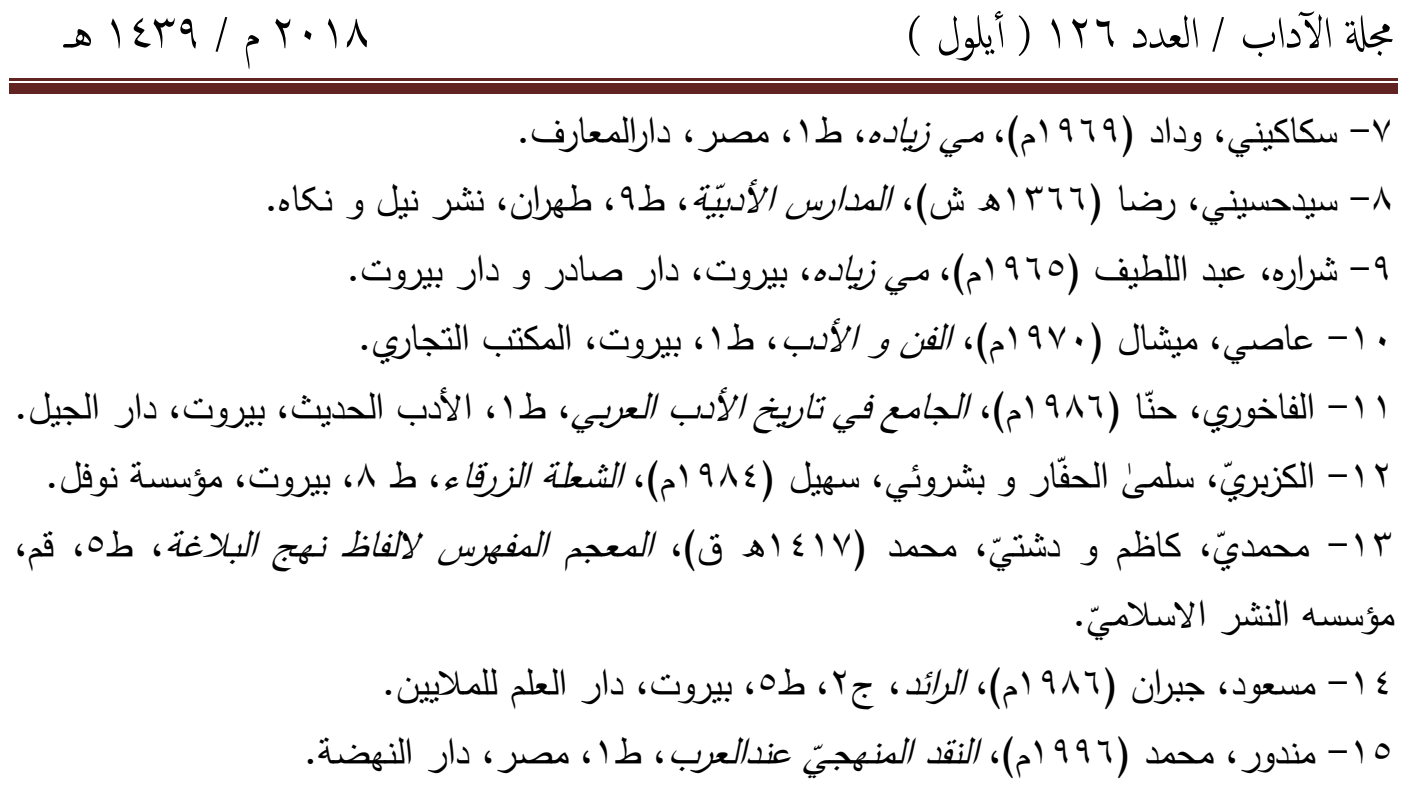

\section{Mei ziadah a woman of Letters Between Realism and Romanticism}

Sardare Alani

Associated Professor of Arabic Language \& Literature

Faculty of Foreign Languages, University of Isfahan

\section{Abstract}

Mei ziadah tendencies in beginnings of her social Literary activities to the realism. refused from that and inclined to the Romanticism. She achieved favorable position. Her motives as follows: life positions, especially experiences and essence of literary schools which are as rainbow. Colours are independent while are chaotic. the aims of this research as follows:

Expression of Mei ziadah, social literary position

2- analysis of her' s two literary tendencies

3- clearly traces of Romanticism in her' s works

4- motives of Mei ziadah, s refuse from Realism and tendency to Romanticism.

Keywords: Mei ziadah, Realism, Romanticism, Literary schools literary tendencies 